IZA DP No. 5023

Uniform and Nonuniform Staggering of Wage Contracts

Leif Danziger

June 2010 


\title{
Uniform and Nonuniform Staggering of Wage Contracts
}

\author{
Leif Danziger \\ Ben-Gurion University, \\ CESifo and IZA
}

Discussion Paper No. 5023

June 2010

IZA

P.O. Box 7240

53072 Bonn

Germany

Phone: +49-228-3894-0

Fax: +49-228-3894-180

E-mail: iza@iza.org

\begin{abstract}
Any opinions expressed here are those of the author(s) and not those of IZA. Research published in this series may include views on policy, but the institute itself takes no institutional policy positions.

The Institute for the Study of Labor (IZA) in Bonn is a local and virtual international research center and a place of communication between science, politics and business. IZA is an independent nonprofit organization supported by Deutsche Post Foundation. The center is associated with the University of Bonn and offers a stimulating research environment through its international network, workshops and conferences, data service, project support, research visits and doctoral program. IZA engages in (i) original and internationally competitive research in all fields of labor economics, (ii) development of policy concepts, and (iii) dissemination of research results and concepts to the interested public.
\end{abstract}

IZA Discussion Papers often represent preliminary work and are circulated to encourage discussion. Citation of such a paper should account for its provisional character. A revised version may be available directly from the author. 
IZA Discussion Paper No. 5023

June 2010

\section{ABSTRACT}

\section{Uniform and Nonuniform Staggering of Wage Contracts}

This paper provides a model that can account for the almost uniform staggering of wage contracts in some countries as well as for the markedly nonuniform staggering in others. In the model, short and long contracts as well as long contracts concluded in different periods are strategic substitutes, which provides a powerful rationale for staggering. We show that for realistic parameter values, there is a continuum of possible equilibria with various degrees of staggering of long contracts. If the contracting cost is not too large, then the lowest possible degree of staggering decreases with the contracting cost and increases with monetary uncertainty.

JEL Classification: E31, E32, J41

Keywords: uniform staggering, nonuniform staggering, monetary policy shocks, strategic substitutability, wage contracts, contract duration

Corresponding author:

Leif Danziger

Department of Economics

Ben-Gurion University

Beerh-Sheva 84105

Israel

E-mail: danziger@bgu.ac.il 


\section{Introduction}

Wage contracts are almost uniformly staggered in some countries, but markedly nonuniformly staggered in others. This may have important policy implications since the staggering pattern of wage contracts play a central role in many macroeconomic models. In particular, monetary policy shocks may lead to different output responses depending on the proportion of wage contracts that are reset at the same time as the shock. Usually, however, there is no modelling of the economic forces that determine the staggering pattern which is taken as exogenous. The purpose of this paper is therefore to provide a theoretical analysis of the staggering pattern of wage contracts, and to determine how the pattern is influenced by the contracting cost, monetary uncertainty, and various other variables. ${ }^{1}$

Our model assumes that firms and workers may conclude either short contracts (covering one period) or long contracts (covering two periods), and that the economy is exposed to both monetary policy shocks and productivity shocks. Furthermore, the firms produce a homogenous output that is sold in a competitive product market, all firms are equally productive, and the monetary authority follows a passive monetary policy. ${ }^{2}$

In our framework there is strategic substitutability between short and long contracts, as well as between long contracts that are concluded in different periods, and this affects the

\footnotetext{
${ }^{1}$ For empirical evidence about the staggering pattern of contracts, see Matsukawa (1986), Fethke and Policano (1990), and Olivei and Tenreyro (2007, 2008). For theoretical models that show that a staggered wage setting (in contrast to a staggered price setting) is a powerful mechanism for creating a critical nominal friction, see Andersen (1998), Huang and Liu (2002), and Christiano et al. (2005). The distinction between uniform and nonuniform staggering patterns is emphasized in Olivei and Tenreyro (2007, 2008). See also Clarida et al. (1999), Ascari (2000), Erceg et al. (2000), and Smets and Wouters (2007).

${ }^{2}$ We make these assumptions to preclude that staggering of wage contracts could be caused by monopolistic competition, informational asymmetries, idiosyncratic shocks, or systematic interventions by the monetary authority. The competitive product market entails that there is no strategic complementarity in price setting behavior and hence no persistent real effects of monetary policy shocks. Presumably, the introduction of monopolistic competition with the ensuing strategic complementarity in price setting would mitigate, albeit not eliminate, the strategic substitutability between wage contracts that generates the results in this paper. Fethke and Policano (1990) show that if there are both competitive and monopolistically competitive sectors, then informational asymmetries together with a real balance effect may lead to a nonuniform contracting pattern, while Matsukawa (1986) and Fethke and Policano (1987) show that an activist monetary authority may support a nonuniform contracting pattern. See also Fethke and Policano (1986) and Ball (1987).
} 
choice of contract duration and provides a powerful rationale for staggering. To explain what causes strategic substitutability, we note that given its own real wage rate, any firm benefits from the other firms paying higher real wage rates as this increases the equilibrium price of output. If firms with continuing wage contracts pay a real wage that exceeds (is less than) the real wage rate paid by firms with new wage contracts, then the wage index increases (decreases) with the proportion of firms with continuing wage contracts. Furthermore, the larger the proportion of these firms, the less (more) their real profit increases (decreases) relative to the real profits of the firms with a new wage contracts. As a consequence, an increase in the proportion of firms with existing contracts leads to a decrease in the expected real profit from an existing contract relative to the expected real profit from a new contract. The upshot is that contracts of different lengths, as well as contracts of the same length that are concluded in different periods, are strategic substitutes.

We find that for calibrated parameter values, all contracts are long and there is a continuum of possible equilibria with different degrees of staggering. If the contracting cost is not too large, there exists a positive lowest degree of staggering such that there is an equilibrium for any contracting pattern with at least this degree of staggering (and hence with uniformly staggered contracts), but not for any contracting pattern with less staggering (and hence ruling out completely synchronized contracts). For a large value of the contracting cost, the staggering pattern may be very nonuniform, and there is a continuum of equilibria with the contracts being anything from uniformly staggered to completely synchronized. Thus, the model can account for the almost uniform staggering of wage contracts found in some countries as well as for the notably nonuniform staggering found in others. We also show that for less realistic parameter values all contracts may be short (in which case the question of staggering is moot), or short and long contracts may coexist (in which case the latter are uniformly staggered).

The comparative-static analysis shows that if all contracts are long and the lowest possible degree of staggering is positive, then that lowest degree of staggering decreases with the contracting cost and increases with the variance of the monetary policy shocks. Thus, 
the impact of a higher contracting cost and of a higher variance of the monetary policy shocks are in opposite directions. The intuition for this is as follows: On the one hand, a higher contracting cost reduces the attractiveness of concluding short rather than long contracts, and thereby also of deviating from a given pattern of staggered long contracts by concluding a short contract. On the other hand, increased monetary uncertainty has a more negative impact in the second period of a long contract than in a short contract covering the same period. Therefore, it increases the attractiveness of concluding short rather than long contracts, and thereby also of deviating from a given pattern of staggered long contracts.

\section{The Model}

We consider an economy with a unit continuum of firms that produce a homogeneous output which is sold in a competitive market. The firms are labelled by $i \in[0,1]$. The production function of the $i$ th firm in period $t$ is $y_{i t}=a_{t} \ell_{i t}^{x}$, where $y_{i t}$ is the firm's output, $a_{t}$ is the level of aggregate productivity, $\ell_{i t}$ is the firm's labor input, and $x \in(0,1)$. Since $\ell_{i t}=\left(y_{i t} / a_{t}\right)^{1 / x}$ of labor is required to produce $y_{i t}$, the $i$ th firm's nominal profit from production in period $t$ is

$$
p_{t} y_{i t}-w_{i t}\left(\frac{y_{i t}}{a_{t}}\right)^{1 / x}
$$

where $p_{t}$ is the nominal price of output and $w_{i t}$ is the nominal wage rate paid by the $i$ th firm. Given $p_{t}$ and $w_{i t}$, the $i$ th firm maximizes its profit by producing

$$
y_{i t}=a_{t}^{1 /(1-x)}\left(\frac{p_{t} x}{w_{i t}}\right)^{x /(1-x)} .
$$

It follows that the aggregate production is

$$
\begin{aligned}
\int_{0}^{1} y_{i t} d i & =\int_{0}^{1} a_{t}^{1 /(1-x)}\left(\frac{p_{t} x}{w_{i t}}\right)^{x /(1-x)} d i \\
& =a_{t}^{1 /(1-x)}\left(\frac{p_{t} x}{W_{t}}\right)^{x /(1-x)}
\end{aligned}
$$

where

$$
W_{t} \equiv\left[\int_{0}^{1} \frac{1}{w_{i t}^{x /(1-x)}} d i\right]^{(x-1) / x}
$$


is an index of the wage rates in the economy.

The aggregate demand in period $t$ equals the money supply, $M_{t}$. In order for the real demand to equal supply, we must have that

$$
\frac{M_{t}}{p_{t}}=a_{t}^{1 /(1-x)}\left(\frac{p_{t} x}{W_{t}}\right)^{x /(1-x)},
$$

which implies that the equilibrium price is

$$
p_{t}=\frac{M_{t}^{1-x} W_{t}^{x}}{a_{t} x^{x}}
$$

Substituting the equilibrium price in eq. (2) shows that the $i$ th firm will produce

$$
y_{i t}=\frac{a_{t} M_{t}^{x} W_{t}^{x^{2} /(1-x)} x^{x}}{w_{i t}^{x /(1-x)}} .
$$

Then, by dividing the nominal profit in eq. (1) by $p_{t}$ and substituting $p_{t}$ and $y_{i t}$, we obtain that the $i$ th firm's real profit from production in period $t$ is

$$
\frac{a_{t} M_{t}^{x} W_{t}^{x^{2} /(1-x)} x^{x}(1-x)}{w_{i t}^{x /(1-x)}} .
$$

The future money supply and aggregate productivity are uncertain since both are exposed to shocks between periods. Thus, the money supply changes according to $M_{t} / M_{t-1}=$ $(1+\mu)\left(1+\gamma_{t}\right)$, where $\mu$ is the constant trend in the money supply and $\gamma_{t}$ is the monetary policy shock between period $t-1$ and period $t$. The monetary policy shocks are non-degenerate i.i.d. random variables with zero mean. The aggregate productivity changes according to $a_{t} / a_{t-1}=(1+\xi)\left(1+\alpha_{t}\right)$, where $\xi$ is the constant trend in aggregate productivity and $\alpha_{t}$ is the productivity shock between period $t-1$ and period $t$. The productivity shocks are i.i.d. random variables with zero mean.

Each firm concludes consecutive wage contracts with its workers, such that when one contract expires, the next is concluded. A wage contract may cover one period, which is called a short contract, or it may cover two periods, which is called a long contract. ${ }^{3}$ We

\footnotetext{
${ }^{3}$ A contract cannot cover more than two periods since the cumulative effect of shocks might then make it worthwhile for either the firm or the workers to renege on the contract.
} 
assume that the firm's and the workers' bargaining powers are such that the wage rate in a short contract as well as in the first period of a long contract will equal a proportion $\kappa$ of the aggregate demand in the bargaining period (i.e., for a contract negotiated in period $t$ the wage rate will be $\kappa M_{t}$ ), and that the wage rate in the second period of a long contract will equal the same proportion $\kappa$ of the expected aggregate demand in that period (i.e., for a long contract negotiated in period $t-1$ the wage rate in the second period will be $\left.\kappa \mathrm{E}_{t-1} M_{t}=\kappa M_{t} /\left(1+\gamma_{t}\right)\right) .^{4}$

The wage index in period $t$ depends on how many contracts are concluded in period $t$ and how many were concluded in period $t-1$. Let $n_{t}$ denote the proportion of firms that conclude long contracts in period $t$. Then $n_{t} \in\left[0,1-n_{t-1}\right]$, and $1-n_{t}-n_{t-1}$ is the proportion of firms that conclude short contracts in period $t$. Since the wage rate in period $t$ equals $\kappa M_{t}$ for the $1-n_{t-1}$ firms that conclude contracts in period $t$ and equals $\kappa M_{t} /\left(1+\gamma_{t}\right)$ for the $n_{t-1}$ firms that concluded long contracts in period $t-1$, we obtain from eq. (3) that the wage index in period $t$ is

$$
\begin{aligned}
W_{t} & =\left\{\frac{1-n_{t-1}}{\left(\kappa M_{t}\right)^{x /(1-x)}}+\frac{n_{t-1}}{\left[\kappa M_{t} /\left(1+\gamma_{t}\right)\right]^{x /(1-x)}}\right\}^{(x-1) / x} \\
& =\kappa M_{t}\left(1-n_{t-1}+n_{t-1} B_{t}\right)^{(x-1) / x}
\end{aligned}
$$

Here, $B_{t} \equiv\left(1+\gamma_{t}\right)^{x /(1-x)}$ is the ratio of the output of a firm that is in the second period of a long contract concluded in period $t-1$ to the output of a firm that concludes a new contract in period $t$. Thus, if $n_{t-1}=0$ and all the firms conclude new contracts in period $t$, the index in period $t$ is $\kappa M_{t}$. Conversely, if $n_{t-1}=1$ and none of the firms conclude new contracts in period $t$, the index in period $t$ is $\kappa M_{t} /\left(1+\gamma_{t}\right)$. More generally, since $B_{t}$ increases with the monetary policy shock, unless all the contracts are concluded in period $t$, for a given money supply in period $t$ the effect of the second-period wage rates in the long contracts will cause

\footnotetext{
${ }^{4}$ Since $\mathrm{E}_{t-1} M_{t}=(1+\mu) M_{t-1}$, if $\mu=0$, then the wage rate is the same in the two contract periods as in Taylor (1980). More generally, the wage rate in the second period of a long contract might be a different proportion of the expected aggregate demand in that period. The proportion could depend on $x$ and the monetary uncertainty, as long as it approaches $\kappa$ if the monetary uncertainty tends to zero (otherwise output could fluctuate in the absence of shocks).
} 
the wage index in period $t$ to decrease with the monetary policy shock between periods $t-1$ and $t$.

Now, let us suppose that the $i$ th firm concludes a short contract in period $t$. By substituting $w_{i t}=\kappa M_{t}$ and $W_{t}$ from eq. (5) in eq. (4), we obtain that its real profit from production in period $t$ is

$$
\begin{aligned}
& \frac{a_{t} x^{x}(1-x)}{\left(1-n_{t-1}+n_{t-1} B_{t}\right)^{x} \kappa^{x}} \\
= & a_{t} k A_{n_{t-1}, t},
\end{aligned}
$$

where

$$
\begin{aligned}
k & \equiv \frac{x^{x}(1-x)}{\kappa^{x}} \\
A_{n t} & \equiv \frac{1}{\left(1-n+n B_{t}\right)^{x}} .
\end{aligned}
$$

Thus, the real profit from production in period $t$ is proportional to $a_{t}$ and fully incorporates the productivity shock between period $t-1$ and period $t$. The factor $A_{n_{t-1}, t}$, which depends on $n_{t-1}$, embodies the effect of the monetary policy shock between period $t-1$ and period $t$ on the real profit from production in period $t$.

Suppose that, instead, the $i$ th firm concludes a long contract in period $t$. Its real profit from production in the first period of the contract would be the same as the real profit in a short contract. To determine the real profit from production in the second period of the contract, we first advance the period index from $t$ to $t+1$ in eq. (4) and in eq. (5) to show that the real profit from production in period $t+1$ is

$$
\frac{a_{t+1} M_{t+1}^{x} W_{t+1}^{x^{2} /(1-x)} x^{x}(1-x)}{w_{i, t+1}^{x /(1-x)}},
$$

while the wage index in period $t+1$ is

$$
W_{t+1}=\kappa M_{t+1}\left(1-n_{t}+n_{t} B_{t+1}\right)^{(x-1) / x} .
$$

We then substitute $w_{i, t+1}=\kappa M_{t+1} /\left(1+\gamma_{t+1}\right)$, and $W_{t+1}$ in expression (6) to obtain that the real profit from production in the second period of the contract concluded in period $t$ is

$$
\frac{a_{t+1} B_{t+1} x^{x}(1-x)}{\left(1-n_{t}+n_{t} B_{t+1}\right)^{x} \kappa^{x}}
$$




$$
=a_{t+1} k A_{n_{t}, t+1} B_{t+1} \text {. }
$$

At each $t$ in which a firm negotiates a new contract, it chooses whether the contract should be short (i.e., cover only $t$ ) or long (i.e., cover both $t$ and $t+1$ ). In order to negotiate a contract, the firm incurs a real contracting cost that is proportional to the real profit in the contracting period in the absence of a monetary policy shock. That is, the real contracting cost in period $t$ is $c k a_{t}$, where $c \geq 0$. A firm's real profit in period $t$ can therefore be written as $a_{t} k\left(A_{n_{t-1, t}} B_{t}^{1-\lambda_{t}}-\lambda_{t} c\right)$, where $\lambda_{t}=1$ if a new contract is negotiated in period $t$, and $\lambda_{t}=0$ if a long contract was negotiated in period $t-1$.

A firm's objective is to maximize its discounted expected real profits

$$
k \mathrm{E}_{t} \sum_{\tau=t}^{\infty} \frac{a_{\tau}\left(A_{n_{\tau-1, \tau}} B_{\tau}^{1-\lambda_{\tau}}-\lambda_{\tau} c\right)}{(1+\rho)^{\tau-t}},
$$

where $\rho$ is the discount rate, and the expectation at $t$ is taken over the distribution of all future real profits. It is assumed that $\rho>\xi$ in order for the discounted expected real profits to be bounded. The firm's discounted expected real profits depend on the firm's and all the other firms' choices of contracts in the present and future, and each firm's contracting strategy maps all available information to a choice of either a short or a long contract at each $t$ that a new contract is negotiated. We consider only Markov contracting strategies, that is, strategies for which a firm's current choice between concluding a short or a long contract depends on only the available information that directly affects the firm's current or future real profits.

Definition. The economy is in a Markov perfect contracting equilibrium if in each period that a firm negotiates a new contract, the firm's Markov contracting strategy maximizes its discounted expected real profits given that all other firms follow their Markov contracting strategies.

\section{Contract Characteristics}

Firms that always conclude short contracts are called short-contract firms, and firms that always conclude long contracts are called long-contract firms. The latter are subdivided into 
even firms that always conclude long contracts in even-numbered periods, and odd firms that always conclude long contracts in odd-numbered periods.

We now proceed to establish Lemma 1 which derives the expressions for short- and longcontract firms' discounted expected real profits; Lemma 2 which uses these expressions to determine the short- and long-contract firms' gains from a one-time deviation; and Lemma 3 which implies strategic substitutability between short and long contracts as well as strategic substitutability between long contracts concluded in even-numbered periods and long contracts concluded in odd-numbered periods. ${ }^{5}$

\subsection{The Discounted Expected Real Profits for Short- and Long- Contract Firms}

Let $T_{e}$ denote an arbitrary even-numbered period and $T_{o}$ an arbitrary odd-numbered period. Define $\delta \equiv(1+\rho) /(1+\xi)-1$, which is positive. We now determine the discounted expected real profits for a short-contract firm, an even firm, and an odd firm:

Lemma 1. Assume that there are $n_{e} \in[0,1]$ even firms, $n_{o} \in\left[0,1-n_{e}\right]$ odd firms, and that the remaining firms are short-contract firms. The discounted expected real profits at $T_{e}$ for a short-contract firm are

$$
a_{T_{e}} k\left[A_{n_{o}, T_{e}}+\frac{\mathrm{E}_{t-1} A_{n_{o}, t}+(1+\delta) \mathrm{E}_{t-1} A_{n_{e}, t}}{\delta(2+\delta)}-\frac{(1+\delta) c}{\delta}\right],
$$

and for an even firm are

$$
a_{T_{e}} k\left[A_{n_{o}, T_{e}}+\frac{\mathrm{E}_{t-1} A_{n_{o}, t}+(1+\delta) \mathrm{E}_{t-1}\left(A_{n_{e}, t} B_{t}\right)-(1+\delta)^{2} c}{\delta(2+\delta)}\right] .
$$

The discounted expected real profits at $T_{o}$ for a short-contract firm are

$$
a_{T_{o}} k\left[A_{n_{e}, T_{o}}+\frac{\mathrm{E}_{t-1} A_{n_{e}, t}+(1+\delta) \mathrm{E}_{t-1} A_{n_{o}, t}}{\delta(2+\delta)}-\frac{(1+\delta) c}{\delta}\right]
$$

\footnotetext{
5 The proofs of Lemmas 1-3 are in Appendix A.
} 
and for an odd firm are

$$
a_{T_{o}} k\left[A_{n_{e}, T_{o}}+\frac{\mathrm{E}_{t-1} A_{n_{e}, t}+(1+\delta) \mathrm{E}_{t-1}\left(A_{n_{o}, t} B_{t}\right)-(1+\delta)^{2} c}{\delta(2+\delta)}\right] .
$$

To understand Lemma 1, assume that $a_{T_{e}} k=1$. Consider first expression (7) for a short-contract firm's discounted expected real profits. The first term in the brackets of expression (7) is the real profit from production in period $T_{e}$. To explain the next term in the brackets, we note that $\delta$ may be interpreted as the discount rate modified for the effect of the anticipated changes in the aggregate productivity on expected future real profits, and that random changes in the aggregate productivity have no effect on expected future real profits. Thus, the discounted expected real profit from production in any future evennumbered period equals $\mathrm{E}_{t-1} A_{n_{o}, t}$, which is what the expected real profit from production would be in any such future period if it were known that the aggregate productivity would remain unchanged, discounted $t_{e}-T_{e}$ periods with the modified discount rate $\delta$. Similarly, the discounted expected real profit from production in any future odd-numbered period equals $\mathrm{E}_{t-1} A_{n_{e}, t}$, which is what the expected real profit from production would be in any future odd-numbered period if it were known that the aggregate productivity would remain unchanged, discounted $t_{o}-T_{o}$ periods with the modified discount rate $\delta$. Accordingly, the second term in the brackets of expression (7) is the sum of the expected real profits from production in all future even- and odd-numbered periods if it were known that the aggregate productivity would remain unchanged, discounted the relevant number of periods with the modified discount rate. That is, the second term consists of $\mathrm{E}_{t-1} A_{n_{o}, t}$ multiplied by $1 /(1+\delta)^{2}+1 /(1+\delta)^{4}+\ldots=1 /[\delta(2+\delta)]$ plus $\mathrm{E}_{t-1} A_{n_{e}, t}$ multiplied by $1 /(1+\delta)+1 /(1+\delta)^{3}+\ldots=$ $(1+\delta) /[\delta(2+\delta)]$. The third term in the brackets of expression (7) stems from the discounted expected real cost of contracting in each period.

Consider next expression (8) for an even firm's discounted expected real profits. Since the real profit from production in the first period of any long contract is the same as in a short contract, the real profit from production in period $T_{e}$ and the discounted expected 
real profits from production in all future even-numbered periods are the same as with short contracts. However, the real profit from production in the second period of a long contract is generally different from what it would be in a short contract, and the discounted expected real profit from production in an odd-numbered period $t_{o}$ (which is the second period of a contract) equals $\mathrm{E}_{t-1}\left(A_{n_{e}, t} B_{t}\right)$, discounted $t_{o}-T_{e}$ periods with the modified discount rate $\delta$. Hence, the discounted expected real profits from production in all odd-numbered periods are $(1+\delta) \mathrm{E}_{t-1}\left(A_{n_{e}, t} B_{t}\right) /[\delta(2+\delta)]$ rather than $(1+\delta) \mathrm{E}_{t-1} A_{n_{e}, t} /[\delta(2+\delta)]$ as they would be in the case of short contracts. Finally, the sum of the discounted expected real cost of contracting is less for a long-contract firm than for a short-contract firm. Expressions (9) and (10) for the discounted expected real profits at $T_{o}$ for a short-contract firm and for an odd firm have a similar interpretation.

\subsection{The Gain from a One-Time Deviation}

We proceed to determine the gain to a deviating short-contract firm, by which we mean a short-contract firm that makes a one-time deviation by concluding a long contract and then reverts to always concluding short contracts. We also determine the gain to a deviating even (odd) firm, by which we mean an even (odd) firm that makes a one-time deviation by concluding a short contract in an even-numbered (odd-numbered) period and then reverts to always concluding long contracts. Let

$$
\begin{aligned}
D(n) & \equiv \underset{t-1}{\mathrm{E}}\left[A_{n t}\left(B_{t}-1\right)\right]+c, \\
G\left(n^{\prime}, n^{\prime \prime}\right) & \equiv-D\left(n^{\prime}\right)+\frac{D\left(n^{\prime \prime}\right)}{1+\delta} \\
h & \equiv \frac{k(1+\delta)}{\delta(2+\delta)}
\end{aligned}
$$

We then have:

Lemma 2. Assume that there are $n_{e} \in[0,1]$ even firms, $n_{o} \in\left[0,1-n_{e}\right]$ odd firms, and that the remaining firms are short-contract firms. The gain of discounted expected real profits at $T_{e}$ for a deviating short-contract firm is $a_{T_{e}} k D\left(n_{e}\right) /(1+\delta)$, 
and for a deviating even firm is $a_{T_{e}} h G\left(n_{e}, n_{o}\right)$. The gain of discounted expected real profits at $T_{o}$ for a deviating short-contract firm is $a_{T_{o}} k D\left(n_{o}\right) /(1+\delta)$, and for a deviating odd firm is $a_{T_{o}} h G\left(n_{o}, n_{e}\right)$.

Lemma 2 can be understood by observing that if a short-contract firm deviates in period $T_{e}$, then it gains the difference between the discounted expected real profit in the second period of the long contract concluded in period $T_{e}$, that is, $a_{T_{e}} k \mathrm{E}_{t-1}\left(A_{n_{e}, t} B_{t}\right) /(1+\delta)$, and what the discounted expected real profit would be in a short contract concluded in period $T_{e}+1$, that is, $a_{T_{e}} k\left(\mathrm{E}_{t-1} A_{n_{e}, t}-c\right) /(1+\delta)$. By subtracting the latter from the former, one obtains that the gain from deviating is $a_{T_{e}} k D\left(n_{e}\right) /(1+\delta)$.

Similarly, if an even firm deviates in period $T_{e}$, then each of the first (second) periods of the long contracts that the firm will conclude at future odd-numbered (even-numbered) periods corresponds to a second (first) period of one of the long contracts that it would have concluded at even-numbered periods if it had not deviated. Hence, the gain of discounted expected real profit from deviating in period $T_{e}$ stemming from the odd-numbered periods $T_{e}+1, T_{e}+3, \ldots$ is $-a_{T_{e}} h D\left(n_{e}\right)$, while the gain of discounted expected real profit from deviating in period $T_{e}$ stemming from the even-numbered periods $T_{e}+2, T_{e}+4, \ldots$ is $a_{T_{e}} h D\left(n_{o}\right) /(1+\delta)$. Adding the gains stemming from all the odd- and even-numbered periods, the even firm's total gain from deviating is $a_{T_{e}} h G\left(n_{e}, n_{o}\right)$.

The interpretations of the gains for a short-contract firm and for an odd firm from deviating in period $T_{o}$ are similar.

\subsection{Strategic Substitutability between Contracts}

We now establish the fundamental monotonicity property of the $D(n)$ function which underlies the strategic substitutability between short and long contracts as well as between long contracts concluded in even-numbered periods and long contracts concluded in oddnumbered periods:

Lemma 3. $d D(n) / d n<0$. 
If $n_{e} \in[0,1]$ of firms are even, $n_{o} \in\left[0,1-n_{e}\right]$ of firms are odd, and the remaining firms always conclude short contracts, then subtracting (7) from (8) shows that the difference between the discounted expected real profits at $T_{e}$ for an even firm and for a short-contract firm is $a_{T_{e}} h D\left(n_{e}\right)$. Similarly, the difference between the discounted expected real profits at $T_{o}$ for an odd firm and for a short-contract firm is $a_{T_{o}} h D\left(n_{o}\right)$. Lemma 3 therefore implies that the value of always concluding long rather than short contracts decreases with the proportion of long contracts that are concluded in the same periods. Accordingly, long and short contracts are strategic substitutes.

The explanation for the strategic substitutability between long and short contracts is that given its own real wage rate, any firm benefits from a higher wage index as other firms paying higher real wages is associated with a higher equilibrium price. Indeed, eq. (4) shows that given its own real wage rate, the wage index has an equi-proportional effect on each firm's real profit. Now, the wage index in period $t$ increases (decreases) with the proportion of firms that concluded long contracts in period $t-1$ if the wage rate in these firms exceeds (is less than) the wage rate in the firms that conclude new contracts in period $t$. Hence, a larger $n_{t-1}$ leads to a smaller increase (larger decrease) in the real profit in period $t$ of firms that are in the second period of a long contract than for firms that have concluded a short contract if the wage rate in the firms that concluded long contracts in period $t-1$ exceeds (is less than) the wage rate in the firms that conclude new contracts in period $t$. As a consequence, an increase in $n_{t-1}$ decreases the expected real profit of firms that are in the second period of a long contract relative to the expected real profit of firms that have concluded a new contract. That is, $d D(n) / d n<0$ so that long and short contracts are strategic substitutes.

The strategic substitutability between long and short contracts has important implications for the gains of a deviating short-contract firm. According to Lemma 2, if the deviation takes place in an even-numbered period, the gain of discounted expected real profits is proportional to $D\left(n_{e}\right)$ and hence decreases with $n_{e}$, while if the deviation takes place in an odd-numbered period, the gain of discounted expected real profits is proportional to $D\left(n_{o}\right)$ 
and hence decreases with $n_{o}$. In particular, if $D\left(\frac{1}{2}\right)<0<D(0)$, there exists a unique proportion of long-contract firms $m \in\left(0, \frac{1}{2}\right)$ such that $D(m) \gtreqless 0$ as $n \lesseqgtr m$. Hence, a short-contract firm will find it profitable to deviate in an even-numbered period iff $n_{e}<m$, and to deviate in an odd-numbered period iff $n_{o}<m$.

Turning to the case in which there are only long-contract firms (and hence $n_{e}+n_{o}=1$ ), the difference between the discounted expected real future profits at $T_{e}$ for an even firm and for an odd firm is $a_{T_{e}} h\left[D\left(n_{e}\right)-D\left(1-n_{e}\right) /(1+\delta)\right]$. Now, $d D\left(n_{e}\right) / d n_{e}<0$, which reflects that in any future even-numbered period an increase in $n_{e}$ decreases the expected real profit of an even firm (that is in its first contract period) relative to the expected real profit of an odd firm (that is in its second contract period), and $-d D\left(1-n_{e}\right) / d n_{e}<0$, which reflects that in any future odd-numbered period an increase in $n_{e}$ decreases the expected future real profit of an even firm (that is in its second contract period) relative to the expected real profit of an odd firm (that is in its first contract period). Lemma 3 therefore also implies that the value of always concluding long contracts in even-numbered periods rather than in odd-numbered periods decreases with the proportion of long contracts that are concluded in the even-numbered periods. Similarly, the value of always concluding long contracts in oddnumbered periods rather than in even-numbered periods decreases with the proportion of long contracts that are concluded in the odd-numbered periods. Accordingly, long contracts concluded in even- and odd-numbered periods are strategic substitutes.

The strategic substitutability between long contracts concluded in different periods is significant for the gains of a deviating long-contract firm. Lemma 2 shows that if there are only long-contract firms and the deviation takes place in an even-numbered period, then the gain of discounted expected real profits is proportional to $G\left(n_{e}, 1-n_{e}\right)=-D\left(n_{e}\right)+D(1-$ $\left.n_{e}\right) /(1+\delta)$ and hence increases with $n_{e}$. If the deviation takes place in an odd-numbered period, then the gain of discounted expected real profits is proportional to $G\left(n_{o}, 1-n_{o}\right)=$ $-D\left(n_{o}\right)+D\left(1-n_{o}\right) /(1+\delta)$, and hence increases with $n_{o}$. As a result, if $G\left(\frac{1}{2}, \frac{1}{2}\right) \leq 0<G(1,0)$, there exists a unique proportion of even firms $\hat{m} \in\left[\frac{1}{2}, 1\right)$ such that $G(\hat{m}, 1-\hat{m}) \gtreqless 0$ as $n \gtreqless \hat{m}$. Hence, a long-contract firm will find it profitable to deviate in an even-numbered period iff 
$n_{e}>\hat{m}$, and to deviate in an odd-numbered period iff $n_{o}>\hat{m}$.

\section{Markov Perfect Contracting Equilibria}

To prove the existence of Markov perfect contracting equilibria, we first define three threshold values of $c$ :

$$
\begin{aligned}
c_{1} & \equiv \underset{t-1}{\mathrm{E}} A_{0 t}\left(1-B_{t}\right) \\
c_{2} & \equiv \underset{t-1}{\mathrm{E}}\left[A_{1 / 2, t}\left(1-B_{t}\right)\right] \\
c_{3} & \equiv \frac{1}{\delta} \underset{t-1}{\mathrm{E}}\left[(1+\delta) A_{1 t}\left(1-B_{t}\right)-A_{0 t}\left(1-B_{t}\right)\right]
\end{aligned}
$$

Note that $c_{1}<c_{2}<c_{3}$. The properties of the equilibria depend on the value of $c$ relative to these threshold values and and are: ${ }^{6}$

Proposition 1. There exist Markov perfect contracting equilibria in which contracts are either short, even or odd. There are four different regimes:

Regime 1: If $c \leq c_{1}$, then $n_{1}=1$ and $n_{e}=n_{o}=0$;

Regime 2: If $c_{1}<c<c_{2}$, then $n_{1}=1-2 m$ and $n_{e}=n_{o}=m$;

Regime 3: If $c_{2} \leq c<c_{3}$, then $n_{1}=0, n_{e} \in[1-\hat{m}, \hat{m}]$, and $n_{o}=1-n_{e}$;

Regime 4: If $c_{3} \leq c$, then $n_{1}=0, n_{e} \in[0,1]$, and $n_{o}=1-n_{e}$.

We discuss each of these regimes in turn.

Regime 1 assumes that the contracting cost is so small that $c \leq c_{1}$. Since this implies that $D(0) \leq 0$, no short-contract firm can gain by deviating if all the other firms are short-contract firms. The equilibrium is illustrated in Figure 1(a) where the horizontal axis measures $n_{e}$ from left to right, and $n_{o}$ from right to left. The downward-sloping $D\left(n_{e}\right)$ curve shows the

${ }^{6}$ The proof of Proposition 1 is in Appendix B. 
gain of a short-contract firm from deviating in an even-numbered period if $a_{T_{e}} k /(1+\delta)=1$. This gain is always nonpositive. The $D\left(n_{o}\right)$ curve is the reflection of the $D\left(n_{e}\right)$ curve around $n_{e}=\frac{1}{2}$, and it shows the gain of a short-contract firm from deviating in an odd-numbered period if $a_{T_{o}} k /(1+\delta)=1$. Consequently, if $n_{1}=1$ and all firms conclude short contracts, no firm has an incentive to deviate. The economy is therefore in a Markov perfect contracting equilibrium, which is illustrated by the thick dots at $n_{e}=0$ and $n_{o}=0$.

Regime 2 assumes a larger contracting cost satisfying $c_{1}<c<c_{2}$. Since a value of the contracting cost in this range implies that $D\left(\frac{1}{2}\right)<0<D(0)$, a short-contract firm gains from deviating if all the other firms are short-contract firms, but loses from deviating in an even-numbered period if half of the firms are even and loses from deviating in an oddnumbered period if half of the firms are odd. The equilibrium is illustrated in Figure 1(b). The $D\left(n_{e}\right)$ curve intersects the horizontal axis at $m$, where the gain of a short-contract firm from deviating in an even-numbered period vanishes. The upward-sloping $G\left(n_{e}, n_{e}\right)$ curve is the gain of an even firm from deviating in an even-numbered period if $a_{T_{e}} h=1$ and $n_{o}=n_{e}$. Since $G\left(n_{e}, n_{e}\right)=-\delta D\left(n_{e}\right) /(1+\delta)$, this curve likewise intersects the horizontal axis at $m$, where an even firm's gain from deviation also vanishes. If $n_{e}<m$, there are so few even firms that a short-contract firm would gain and an even firm would lose by deviating, while if $n_{e}>m$, there are so many even firms that a short-contract firm would lose and an even firm would gain by deviating. The $D\left(n_{o}\right)$ and $G\left(n_{o}, n_{o}\right)$ curves show the corresponding gains for a firm that deviates in an odd-numbered period. It is apparent that if $n_{1}=1-2 m$ and $n_{e}=n_{o}=m$, then all the firms - whether they conclude short contracts or conclude long contracts in even- or odd-numbered periods - obtain the same discounted expected real profits. No firm, therefore, has an incentive to deviate, and short- and long-contract firms coexist in the Markov perfect contracting equilibrium that is illustrated by the two thick dots at $n_{e}=m$ and $n_{o}=m .^{7} \quad$ As an equal proportion of the long-contract firms conclude contracts in even and odd-numbered periods $\left(n_{e}=n_{o}\right)$, the long contracts are uniformly

\footnotetext{
${ }^{7}$ If $c_{1}<0$, then Regime 1 is empty and some firms conclude long contracts even if there is no contracting cost $(c=0)$.
} 
staggered.

Regime 3 assumes a still larger contracting cost satisfying $c_{2} \leq c<c_{3}$. Since such value of the contracting cost entails that $G\left(\frac{1}{2}, \frac{1}{2}\right) \leq 0<G(1,0)$, a long-contract firm does not gain from deviating if half the firms are even or if half the firms are odd, but gains from deviating if all the other firms have concluded long contracts in the previous period. The equilibrium is illustrated in Figure 1(c). The upward-sloping $G\left(n_{e}, 1-n_{e}\right)$ curve shows an even firm's gain from deviating in an even-numbered period if $a_{T_{e}} h=1$ and $n_{o}=1-n_{e}$. The $G\left(n_{e}, 1-n_{e}\right)$ curve intersects the horizontal axis at $\hat{m}$, where an even firm's gain from deviation vanishes. If $n_{e}<\hat{m}$, there are so many odd firms that an even firm would lose by deviating and becoming an odd firm, while if $n_{e}>\hat{m}$, there are so many even firms that an even firm would gain by deviating and becoming an odd firm. The $G\left(n_{o}, 1-n_{o}\right)$ curve is the reflection of the $G\left(n_{e}, 1-n_{e}\right)$ curve around $n_{e}=\frac{1}{2}$, and it shows an odd firm's gain from deviating in an odd-numbered period if $a_{T_{o}} h=1$ and $n_{e}=1-n_{o}$. This curve intersects the horizontal axis at $n_{o}=\hat{m} \Leftrightarrow n_{e}=1-\hat{m}$, where an odd firm's gain from deviation vanishes. If $n_{o}<\hat{m} \Leftrightarrow n_{e}>1-\hat{m}$, an odd firm would lose by deviating and becoming an even firm, while if $n_{o}>\hat{m} \Leftrightarrow n_{e}<1-\hat{m}$, an odd firm would gain by deviating and becoming an even firm. Accordingly, for $n_{1}=0$ and any $n_{e} \in[1-\hat{m}, \hat{m}]$ and $n_{o}=1-n_{e}$, there are no short-contract firms and neither even nor odd firms have an incentive to deviate. The economy is therefore in a Markov perfect contracting equilibrium with all contracts being long. The range of possible equilibria are illustrated by the thick line between $n_{e}=1-\hat{m}$ and $n_{e}=\hat{m}$ in Figure 1(c). Uniform staggering of the contracts is possible, but is only one out of a continuum of possible equilibria. All other equilibria involve nonuniform staggering with different proportions of firms concluding long contracts in even- and odd-numbered periods $\left(n_{e}, n_{o} \neq \frac{1}{2}\right)$.

Finally, Regime 4 assumes that the contracting cost is so large that $c_{3} \leq c$. Since this entails that $G(1,0) \leq 0$, a long-contract firm does not gain from deviating even if all the other firms are even or if all the other firms are odd. The equilibrium is illustrated in Figure $1(\mathrm{~d})$. The $G\left(n_{e}, 1-n_{e}\right)$ curve is never above the horizontal axis, which indicates that 
no long-contract firm has an incentive to deviate in an even-numbered period. Since the $G\left(n_{o}, 1-n_{o}\right)$ curve is similarly never above the horizontal axis, it follows that for $n_{1}=0$ and any $n_{e} \in[0,1]$ and $n_{o}=1-n_{e}$, the economy is in a Markov perfect contracting equilibrium. The possible equilibria are illustrated by the thick line between $n_{e}=0$ and $n_{e}=1$. All contracts cover two periods. Uniform staggering as well as complete synchronization where all firms conclude their contracts in the same periods $\left(n_{e}=1\right.$ or $\left.n_{o}=1\right)$ are possible, but are only two out of a continuum of possible equilibria.

To sum up: Starting with a $c$ smaller than $c_{1}$, the economy will be in Regime 1 in which there are only short contracts. As $c$ is increased and reaches $c_{1}$, the economy will move to Regime 2 in which there are both short and long contracts, and the long-contract firms are uniformly staggered. As $c$ is increased further and reaches $c_{2}$, the economy will move to Regime 3 in which there are only long contracts and a positive lower bound for the degree of staggering. Eventually, as $c$ is increased even further and reaches $c_{3}$, the economy will move to Regime 4 in which there are only long contracts and any degree of staggering (including no staggering at all) can be an equilibrium.

\section{Comparative Statics}

A natural measure of the degree of staggering of long contacts is $\min \left\{n_{e}, n_{o}\right\} / \max \left\{n_{e}, n_{o}\right\}$. The degree of staggering decreases with the majority proportion of long-contract firms (i.e., with $n_{e}$ if $n_{e}>n_{o}$, and with $n_{o}$ if $n_{o}>n_{e}$ ). It equals one if the contracts are uniformly staggered (which necessarily happens in Regime 2 and may happen in Regimes 3 and 4), and equals zero if the contracts are completely synchronized (which may happen only in Regime 4). The lowest degree of staggering that is possible in Regime 3 is given by $s \equiv(1-\hat{m}) / \hat{m}$.

We now determine the comparative-static effects of changes in the parameter values on $m$ in Regime 2 , and on $\hat{m}$ and $s$ in Regime $3 .^{8}$

Proposition 2. $d m / d c>0 ; d \hat{m} / d c>0 ; d s / d c<0$.

\footnotetext{
8 The proofs of Propositions 2-6 are in Appendix C.
} 
In Regime 2, an increase in the contracting cost reduces the attractiveness of the short contracts for any $n$, which increases $m$ and thereby the proportion of long-contract firms. In Figure 1(b), the $D\left(n_{e}\right)$ and $D\left(n_{o}\right)$ curves shift upward, and the $G\left(n_{e}, n_{e}\right)$ and $G\left(n_{o}, n_{o}\right)$ curves shift downward. A higher contracting cost is therefore associated with a longer average contract length.

In Regime 3, an increase in the contracting cost makes it less profitable to deviate for any $n$, which increases $\hat{m}$ and thus widens the equilibrium range of $n$ 's. In Figure 1(c), the $G\left(n_{e}, 1-n_{e}\right)$ and $G\left(n_{o}, 1-n_{o}\right)$ curves shift downward. A higher contracting cost therefore reduces the lowest degree of staggering that is possible in equilibrium. Observe that it is the same logic that compels an increase in the contracting cost to increase the proportion of long-contract firms in Regime 2 and to decrease the lowest possible degree of staggering in Regime 3.

Proposition 3. $d m / d \rho=0 ; d \hat{m} / d \rho>0 ; d s / d \rho<0$.

In order for short and long contracts to coexist in Regime 2, the discounted expected real profits from any long contract must equal the discounted expected real profits from two consecutive short contracts that cover the same two periods. Furthermore, since the real profit in the first period of a long contract equals the real profit in the corresponding first short contract, the expected real profit in the second period of a long contract must equal the expected real profit in the corresponding second short contract. Therefore, in equilibrium the gain from deviation is zero for both short- and long-contract firms, independently of the discount rate. It follows that in Figure 1(b) the point at which the $D\left(n_{e}\right)$ and $G\left(n_{e}, n_{e}\right)$ curves intersect the horizontal axis, and analogously the point at which the $D\left(n_{o}\right)$ and $G\left(n_{o}, n_{o}\right)$ curves intersect the horizontal axis, are independent of $\rho$. Hence, discounting has no bearing on the determination of $m$.

Turning to Regime 3 in which all firms conclude long contracts and there is a positive lower bound for the degree of staggering, observe that $D(1-\hat{m})>0$ and $D(\hat{m})>0$ (since the $D\left(n_{e}\right)$ curve is downward sloping). At $n_{e}=\hat{m}$, therefore, a deviating even firm's gain of discounted expected real profits stemming from odd-numbered periods is negative, while its 
gain of discounted expected real profits stemming from even-numbered periods is positive. In any long contract concluded after the deviation, the first contract period is odd-numbered and the second contract period is even-numbered, so a higher discount rate attaches relatively more weight to the negative gain of expected real profits stemming from the odd-numbered periods than to the positive gain of expected real profits stemming from the even-numbered periods. Accordingly, it becomes less attractive to deviate, which explains why in Figure $1(\mathrm{c})$ the $G\left(n_{e}, 1-n_{e}\right)$ and $G\left(n_{o}, 1-n_{o}\right)$ curves move down. A higher discount rate therefore leads to a higher $\hat{m}$ and thereby to a lower $s$.

Proposition 4. $d m / d \xi=0 ; d \hat{m} / d \xi<0 ; d s / d \xi>0$.

An increase in the productivity trend affects the gain from deviation only because it decreases the modified discount rate. If an increase in the productivity trend has an effect, it will therefore be in the opposite direction of the effect of an increase in the discount rate. Consequently, the productivity trend will have no effect on $m$, a negative effect on $\hat{m}$, and a positive effect on $s$.

Concerning the threshold values of the contracting cost, we have:

Proposition 5. $d c_{1} / d \rho=0 ; d c_{2} / d \rho=0 ; d c_{3} / d \rho<0$.

An increase in the discount rate does not affect $c_{1}$ and $c_{2}$, and hence does not affect the range of contracting costs for which Regime 1 and Regime 2 occur. The reason is that in Regime 1 there are only short-contract firms, and that in Regime 2 short- and long period firms have the same expected real profits in each period. However, an increase in the discount rate reduces $c_{3}$ since in Regime 3 there are only long-contract firms and a higher discount rate makes it less attractive for such firms to deviate for a given contracting cost. Hence, the economy will move from Regime 3 to Regime 4 for a smaller value of the contracting cost.

Proposition 6. $d c_{1} / d \xi=0 ; d c_{2} / d \xi=0 ; d c_{3} / d \xi>0$. 
The productivity trend may affect the threshold values of $c$ only through its negative effect on the modified discount rate. Therefore, an increase in the productivity trend has no effect on $c_{1}$ and $c_{2}$ (since these are not affected by the discount rate) and affects $c_{3}$ positively (since an increase in the discount rate affects $c_{3}$ negatively).

Finally, we note that the trend in the money supply and the uncertainty of aggregate productivity have no effect on the Markov perfect contracting equilibrium, and a fortiori, on $m, \hat{m}$, and $s$, as well as on the threshold values of the contracting cost. The former follows from the fact that the current and future real wages in both short or long contracts are independent of the trend in the money supply, which hence does not affect the firms' gains from deviation. The latter follows from the fact that the real wages in both short and long contracts are proportional to aggregate productivity. Therefore, the uncertainty of aggregate productivity (as opposed to the trend in the aggregate productivity and the realized productivity shocks) does not affect the current real wage or the expected future real wages in short or long contracts, and hence also does not affect the firms' discounted expected real profits and their gains from deviation.

\section{Analytical Approximations}

For low levels of monetary uncertainty, it is possible to derive simple analytical approximations for $m, \hat{m}$, and $s$, which we denote by $m^{*}, \hat{m}^{*}$, and $s^{*}$. To derive $m^{*}$, we expand $D(m)$ around $\gamma_{t}=0$. By ignoring terms with $\gamma_{t}$ of higher order than two and using that $\mathrm{E}_{t-1} \gamma_{t}=0$, we can approximate $D(m)$ by

$$
\frac{x\left(2 x-1-2 m x^{2}\right) \sigma^{2}}{2(1-x)^{2}}+c,
$$

where $\sigma^{2} \equiv \mathrm{E}_{t-1} \gamma_{t}^{2}$ is the variance of the monetary policy shocks. Setting this expression equal to zero, we obtain that for low levels of monetary uncertainty, $m$ is approximately

$$
m^{*}=\frac{2 x^{2}-x+2(1-x)^{2} c / \sigma^{2}}{2 x^{3}} .
$$


To derive $\hat{m}^{*}$, we expand $G(\hat{m}, 1-\hat{m})$ around $\gamma_{t}=0$. By ignoring terms with $\gamma_{t}$ of a higher order than two and again noting that $\mathrm{E}_{t-1} \gamma_{t}=0$, we can approximate $G(\hat{m}, 1-\hat{m})$ by

$$
\frac{\left[\delta x(1-2 x)-2 x^{3}+2 \hat{m}(2+\delta) x^{3}\right] \sigma^{2}}{2(1+\delta)(1-x)^{2}}-\frac{\delta c}{1+\delta} .
$$

Setting this expression equal to zero, for low levels of monetary uncertainty $\hat{m}$ is approximately

$$
\hat{m}^{*}=\frac{1}{2}+\frac{\delta\left(-x+2 c / \sigma^{2}\right)(1-x)^{2}}{2(2+\delta) x^{3}} .
$$

Hence, $s$ is approximately

$$
s^{*}=\frac{1-\hat{m}^{*}}{\hat{m}^{*}} \text {. }
$$

It is clear from the expressions for $m^{*}, \hat{m}^{*}$, and $s^{*}$ that $c, \rho$, and $\xi$ affect the approximate values of $m, \hat{m}$, and $s$ in the same way as they affect the exact values of these variables. It is also apparent that the variance of the monetary policy shocks has a negative effect on $m^{*}$ and $\hat{m}^{*}$, and a positive effect on $s^{*}$. Thus, we have

Proposition 7. $d m^{*} / d \sigma^{2}<0 ; d \hat{m}^{*} / d \sigma^{2}<0 ; d s^{*} / d \sigma^{2}>0$.

As expected, an increase in the variance of the monetary policy shocks has the opposite effects of an increase in the contracting cost. The logic for this is straightforward in that firms with long contracts are more exposed to monetary uncertainty than firms with short contracts. In Regime 2, therefore, an increase in the monetary uncertainty would give a long-contract firm an incentive to deviate if the proportion of long-contract firms remains unchanged. Since the gain of a long-contract firm from deviating decreases with the proportion of long-contract firms, that proportion - i.e., $m^{*}$ - must decrease in order to eliminate the incentive to deviate. ${ }^{9}$

\footnotetext{
${ }^{9}$ Hence, the average contract duration increases with the contracting cost and decreases with the variance of the monetary policy shocks. A similar result has been obtained by Gray (1978) in a macroeconomic setting that assumes complete synchronization of all contracts, and by Dye (1985), Harris and Holmstrom (1987), and Danziger (1988) in a partial equilibrium setting. Empirical support can be found in Ehrenberg et al. (1984), Christofides (1990), Murphy (1992), Wallace (2001), Rich and Tracy (2004), and Christofides and Peng (2006).
} 
The majority proportion of long-contract firms are more exposed to monetary uncertainty than the minority proportion of long-contract firms. In Regime 3, therefore, an increase in the monetary uncertainty would give a firm from the majority proportion of long-contract firms an incentive to deviate if the majority proportion remains unchanged. Since the gain for a deviating firm from the majority proportion of long-contract firms decreases with the size of the majority proportion of these firms, an increase in monetary uncertainty causes the majority proportion of long-contract firms - i.e., $\hat{m}^{*}$ - to decrease in order to eliminate the incentive to deviate. Finally, an increase in the majority proportion of long-contract firms leads to a decrease in the lowest possible degree of staggering, i.e., in $s^{*}$.

We now turn to the approximations for the threshold values $c_{1}, c_{2}$, and $c_{3}$, which are denoted by $c_{1}^{*}, c_{2}^{*}$, and $c_{3}^{*}$. By expanding $c_{1}, c_{2}$, and $c_{3}$ around $\gamma_{t}=0$, and again ignoring terms with $\gamma_{t}$ of higher order than two and using that $\mathrm{E}_{t-1} \gamma_{t}=0$, we obtain that

$$
\begin{aligned}
c_{1}^{*} & =\frac{x(1-2 x) \sigma^{2}}{2(1-x)^{2}}, \\
c_{2}^{*} & =\frac{1}{2} x \sigma^{2}, \\
c_{3}^{*} & =\frac{x\left[\delta\left(1-2 x+2 x^{2}\right)+2 x^{2}\right] \sigma^{2}}{2 \delta(1-x)^{2}} .
\end{aligned}
$$

Like the exact threshold values, $c_{1}^{*}$ and $c_{2}^{*}$ are independent of $\rho$ and $\xi$, while $c_{3}^{*}$ decreases with $\rho$ and increases with $\xi$. Furthermore, we have

Proposition 8. $d c_{1}^{*} / d \sigma^{2}>0$ if $x>\frac{1}{2} ; d c_{2}^{*} / d \sigma^{2}>0 ; d c_{3}^{*} / d \sigma^{2}>0$.

Thus, all the approximate threshold values of the contracting cost increase with the variance of the monetary policy shocks. ${ }^{10}$ This reflects the fact that increased riskiness of monetary shocks makes long-contract firms more willing to deviate for a given contracting cost. It follows then that with more monetary uncertainty, the economy will move from one regime to the next for higher values of the contracting cost.

\footnotetext{
${ }^{10}$ If $x<\frac{1}{2}$, then $c_{1}^{*}<0$ and Regime 1 cannot exist, while if $x=\frac{1}{2}$, then $c_{1}^{*}=0$ and Regime 1 can emerge only if $c=0$.
} 


\section{Calibration}

In order to assess the empirical relevance of the different regimes, we calibrate the model with realistic benchmark values of the parameters. A standard value for $x$ is $x=\frac{2}{3}$, which implies that $c_{1}^{*}<0$. Therefore, Regime 1 , in which all contracts are short, cannot materialize. Further, assuming that each period in the model corresponds to a year, we set $\rho=0.03$ and $\xi=0.02$. Hence, $\delta=0.01$, which implies that $c_{2}^{*} \simeq 0.333 \sigma^{2}$ and $c_{3}^{*} \simeq 268 \sigma^{2}$. It follows that Regime 2 will emerge if the contracting cost is less than $0.333 \sigma^{2}$ of a firm's real profit; Regime 3 will emerge if the contracting cost is at least $0.333 \sigma^{2}$ and less than $268 \sigma^{2}$ of a firm's real profit, and Regime 4 will emerge if the contracting cost is at least $268 \sigma^{2}$ of a firm's real profit. Setting $\sigma^{2} \in[0.0001,0.001]$, we obtain that $c_{2}^{*}$ is between $0.00333 \%$ and $0.0333 \%$, and that $c_{3}^{*}$ is between $2.68 \%$ and $26.8 \%$. Therefore, the empirical value of $c_{2}^{*}$ is very small, while the empirical value of $c_{3}^{*}$ is large and implies that the contracting cost constitutes a significant proportion of a firm's real profit. Consequently, Regime 2, in which there are both short and long contracts, is probably also not empirically plausible. Thus, it seems likely that it will be a regime with only long contracts that materializes in equilibrium. Hence, if the contracting cost is not too large, then both uniform and moderately nonuniform staggering of long contracts are feasible equilibrium outcomes, ${ }^{11}$ while if the contracting cost is large, then long contracts can be notably nonuniformly staggered. Thus, the model is consistent with the evidence in Olivei and Tenreyro $(2007,2008)$ that contract renewals are more uniformly distributed in Germany, France, and the United Kingdom than in the United States and, in particular, Japan.

\section{Conclusion}

The model in this paper has endogenized the staggering pattern of wage contracts. The crucial feature of the model is that short and long contracts as well as long contracts concluded in different periods are strategic substitutes, which has important implications for

11 The lowest degree of staggering is approximately $(0.501-1.87 c) /(0.499+1.87 c)$. 
the staggering pattern of long contracts. In particular, we show that in the realistic case where only long contracts exist, uniform staggering is just one out of a continuum of possible equilibria with different degrees of staggering. Furthermore, if the contracting cost is not too large, then the lowest possible degree of staggering decreases with the contracting cost and increases with monetary uncertainty. 


\section{Appendix A}

\section{Proof of Lemma 1}

Consider first a short-contract firm in period $T_{e}$. The firm's real profit in this period is $a_{T_{e}} k\left(A_{n_{o}, T_{e}}-c\right)$, and its discounted expected real profit from a future even-numbered period $t_{e} \in\left\{T_{e}+2, T_{e}+4, \ldots\right\}$ is

$$
\frac{k \mathrm{E}_{T_{e}}\left[a_{t_{e}}\left(A_{n_{o}, t_{e}}-c\right)\right]}{(1+\rho)^{t_{e}-T_{e}}} .
$$

Since $a_{t_{e}}=a_{T_{e}}(1+\xi)^{t_{e}-T_{e}} \prod_{\tau=T_{e}+1}^{t_{e}}\left(1+\alpha_{\tau}\right)$, expression (A1) becomes

$$
\begin{aligned}
& \frac{a_{T_{e}}(1+\xi)^{t_{e}-T_{e}} k}{(1+\rho)^{t_{e}-T_{e}}} \underset{T_{e}}{\mathrm{E}}\left[\prod_{\tau=T_{e}+1}^{t_{e}}\left(1+\alpha_{\tau}\right)\left(A_{n_{o}, t_{e}}-c\right)\right] \\
= & \frac{a_{T_{e}} k}{(1+\delta)^{t_{e}-T_{e}}} \underset{T_{e}}{\mathrm{E}}\left[\prod_{\tau=T_{e}+1}^{t_{e}}\left(1+\alpha_{\tau}\right)\left(A_{n_{o}, t_{e}}-c\right)\right] .
\end{aligned}
$$

The independence of the productivity shocks implies that $\mathrm{E}_{T_{e}}\left(1+\alpha_{\tau}\right)=1$ for any $T_{e}$ and $\tau$, while the independence of the monetary policy shocks implies that $\mathrm{E}_{T_{e}} A_{n_{o}, t_{e}}$ is independent of $T_{e}$ and $t_{e}$. Therefore, $\mathrm{E}_{T_{e}} A_{n_{o}, t_{e}}=\mathrm{E}_{t-1} A_{n_{o}, t}$ for any $T_{e}, t_{e}$, and $t$. Accordingly, (A1) can be written as

$$
\frac{a_{T_{e}} k\left(\mathrm{E}_{t-1} A_{n_{o}, t}-c\right)}{(1+\delta)^{t_{e}-T_{e}}}
$$

The discounted expected real profit at $T_{e}$ from a future odd-numbered period $t_{o} \in\left\{T_{e}+\right.$ $\left.1, T_{e}+3, \ldots\right\}$ is

$$
\frac{k \mathrm{E}_{T_{e}}\left[a_{t_{o}}\left(A_{n_{e}, t_{o}}-c\right)\right]}{(1+\rho)^{t_{o}-T_{e}}} .
$$

Using that $a_{t_{o}}=a_{T_{e}}(1+\xi)^{t_{o}-T_{e}} \prod_{\tau=T_{e}+1}^{t_{o}}\left(1+\alpha_{\tau}\right)$, that $\mathrm{E}_{T_{e}}\left(1+\alpha_{\tau}\right)=1$ for any $T_{e}$ and $\tau$, and that $\mathrm{E}_{T_{e}} A_{n_{e}, t_{o}}=\mathrm{E}_{t-1} A_{n_{e}, t}$ for any $T_{e}, t_{o}$, and $t$, expression (A4) becomes

$$
\begin{aligned}
& \frac{a_{T_{e}}(1+\xi)^{t_{o}-T_{e}} k}{(1+\rho)^{t_{o}-T_{e}}} \underset{T_{e}}{\mathrm{E}}\left[\prod_{\tau=T_{e}+1}^{t_{o}}\left(1+\alpha_{\tau}\right)\left(A_{n_{e}, t_{o}}-c\right)\right] \\
= & \frac{a_{T_{e}} k\left(\mathrm{E}_{t-1} A_{n_{e}, t}-c\right)}{(1+\delta)^{t_{o}-T_{e}}} .
\end{aligned}
$$

A short-contract firm's total expected real profits discounted to period $T_{e}$ consists of $a_{T_{e}} k\left(A_{n_{o}, T_{e}}-c\right)$ from period $T_{e}$ plus the sum of (A3) for all future even-numbered periods 
and the sum of (A5) for all future odd-numbered periods. Thus they are

$$
\begin{aligned}
& a_{T_{e}} k\left(A_{n_{o}, T_{e}}-c\right)+\sum_{t_{e}>T_{e}}^{\infty}\left[\frac{a_{T_{e}} k\left(\mathrm{E}_{t-1} A_{n_{o}, t}-c\right)}{(1+\delta)^{t_{e}}-T_{e}}\right]+\sum_{t_{o}>T_{e}}^{\infty}\left[\frac{a_{T_{e}} k\left(\mathrm{E}_{t-1} A_{n_{e}, t}-c\right)}{(1+\delta)^{t_{o}-T_{e}}}\right] \\
= & a_{T_{e}} k\left(A_{n_{o}, T_{e}}-c\right)+\frac{a_{T_{e}} k\left(\mathrm{E}_{t-1} A_{n_{o}, t}-c\right)}{\delta(2+\delta)}+\frac{(1+\delta) a_{T_{e}} k\left(\mathrm{E}_{t-1} A_{n_{e}, t}-c\right)}{\delta(2+\delta)} \\
= & a_{T_{e}} k\left[A_{n_{o}, T_{e}}+\frac{\mathrm{E}_{t-1} A_{n_{o}, t}+(1+\delta) \mathrm{E}_{t-1} A_{n_{e}, t}}{\delta(2+\delta)}-\frac{(1+\delta) c}{\delta}\right] .
\end{aligned}
$$

Consider next an even firm in period $T_{e}$. The firm's real profit in this period and its discounted expected real profit from a future even-numbered period (i.e., in the first period of a future contract) are the same as for a short-contract firm. Its discounted expected real profit at $T_{e}$ from a future odd-numbered period (i.e., in the second period of the present contract or of a future contract) is

$$
\frac{k \mathrm{E}_{T_{e}}\left(a_{t_{o}} A_{n_{e}, t_{o}} B_{t_{o}}\right)}{(1+\rho)^{t_{o}-T_{e}}} .
$$

Since $\mathrm{E}_{T_{e}} a_{t_{o}}=\mathrm{E}_{T_{e}}\left[a_{T_{e}}(1+\xi)^{t_{o}-T_{e}} \prod_{\tau=T_{e}+1}^{t_{o}}\left(1+\alpha_{\tau}\right)\right]=a_{T_{e}}(1+\xi)^{t_{o}-T_{e}}$ for any $T_{e}$ and $\tau$, and $\mathrm{E}_{T_{e}}\left(A_{n_{e}, t_{o}} B_{t_{o}}\right)=\mathrm{E}_{t-1}\left(A_{n_{e}, t} B_{t}\right)$ for any $T_{e}, t_{o}$, and $t$, expression (A7) becomes

$$
\begin{aligned}
& \frac{a_{T_{e}}(1+\xi)^{t_{o}-T_{e}} k}{(1+\rho)^{t_{o}-T_{e}}} \underset{T_{e}}{\mathrm{E}}\left[\prod_{\tau=T_{e}+1}^{t_{o}}\left(1+\alpha_{\tau}\right) A_{n_{e}, t_{o}} B_{t_{o}}\right] \\
= & \frac{a_{T_{e}} k \mathrm{E}_{t-1}\left(A_{n_{e}, t} B_{t}\right)}{(1+\delta)^{t_{o}-T_{e}}} .
\end{aligned}
$$

Consequently, an even firm's total expected real profits discounted to period $T_{e}$ is

$$
\begin{aligned}
& a_{T_{e}} k\left(A_{n_{o}, T_{e}}-c\right)+\sum_{t_{e}>T_{e}}^{\infty}\left[\frac{a_{T_{e}} k\left(\mathrm{E}_{t-1} A_{n_{o}, t}-c\right)}{(1+\delta)^{t_{e}}-T_{e}}\right]+\sum_{t_{o}>T_{e}}^{\infty}\left[\frac{a_{T_{e}} k \mathrm{E}_{t-1}\left(A_{n_{e}, t} B_{t}\right)}{(1+\delta)^{t_{o}}-T_{e}}\right] \\
= & a_{T_{e}} k\left(A_{n_{o}, T_{e}}-c\right)+\frac{a_{T_{e}} k\left(\mathrm{E}_{t-1} A_{n_{o}, t}-c\right)}{\delta(2+\delta)}+\frac{(1+\delta) a_{T_{e}} k \mathrm{E}_{t-1}\left(A_{n_{e}, t} B_{t}\right)}{\delta(2+\delta)} \\
= & a_{T_{e}} k\left[A_{n_{o}, T_{e}}+\frac{\mathrm{E}_{t-1} A_{n_{o}, t}+(1+\delta) \mathrm{E}_{t-1}\left(A_{n_{e}, t} B_{t}\right)-(1+\delta)^{2} c}{\delta(2+\delta)}\right] .
\end{aligned}
$$

We now turn to a short-contract firm in period $T_{o}$. The firm's real profit in this period is $a_{T_{o}} k\left(A_{n_{e}, T_{o}}-c\right)$, its discounted expected real profit from a future odd-numbered period is

$$
\frac{k \mathrm{E}_{T_{o}}\left[a_{t_{o}}\left(A_{n_{e}, t_{o}}-c\right)\right]}{(1+\rho)^{t_{o}-T_{o}}}
$$


and its discounted expected real profit from a future even-numbered period is

$$
\frac{\mathrm{E}_{T_{o}} k\left(a_{t_{e}} A_{n_{o}, t_{e}}-c a_{t_{e}}\right)}{(1+\rho)^{t_{e}-T_{o}}} .
$$

It follows that the short-contract firm's total expected real profits discounted to period $T_{o}$ can be obtained from expression (A6) for a short-contract firm's total expected real profits discounted to period $T_{e}$ by substituting $T_{o}$ for $T_{e}$ and interchanging $n_{o}$ and $n_{e}$. This results in

$$
a_{T_{o}} k\left[A_{n_{e}, T_{o}}+\frac{\mathrm{E}_{t-1} A_{n_{e}, t}+(1+\delta) \mathrm{E}_{t-1} A_{n_{o}, t}}{\delta(2+\delta)}-\frac{(1+\delta) c}{\delta}\right] .
$$

An odd firm's total expected real profits discounted to period $T_{o}$ can be obtained from expression (A8) for an even firm's total expected real profits discounted to period $T_{e}$ by substituting $T_{o}$ for $T_{e}$ and interchanging $n_{o}$ and $n_{e}$. This yields

$$
a_{T_{o}} k\left[A_{n_{e}, T_{o}}+\frac{\mathrm{E}_{t-1} A_{n_{e}, t}+(1+\delta) \mathrm{E}_{t-1}\left(A_{n_{o}, t} B_{t}\right)-(1+\delta)^{2} c}{\delta(2+\delta)}\right] .
$$

\section{Proof of Lemma 2}

Consider first a short-contract firm that deviates in period $T_{e}$ by concluding a long contract, and in period $T_{e}+2$ reverts to always concluding short contracts. The deviating short-contract firm's real profit in period $T_{e}$ and its discounted expected real profits from period $T_{e}+2$ and later periods do not change. Its gain of discounted expected real profits is therefore given by the difference between the discounted expected real profit from the second period of an even contract concluded in period $T_{e}$, i.e., $a_{T_{e}} k \mathrm{E}_{t-1}\left(A_{n_{e}, t} B_{t}\right) /(1+\delta)$, and the discounted expected real profit in a short contract concluded in period $T_{e}+1$, i.e., $a_{T_{e}} k\left(\mathrm{E}_{t-1} A_{n_{e}, t}-c\right) /(1+\delta)$. That is,

$$
\begin{aligned}
& \frac{a_{T_{e}} k \mathrm{E}_{t-1}\left(A_{n_{e}, t} B_{t}\right)}{1+\delta}-\frac{a_{T_{e}} k\left(\mathrm{E}_{t-1} A_{n_{e}, t}-c\right)}{1+\delta} \\
= & \frac{a_{T_{e}} k}{1+\delta} D\left(n_{e}\right) .
\end{aligned}
$$

Consider next an even firm that deviates in period $T_{e}$ by concluding a short contract, and in period $T_{e}+1$ reverts to always concluding long contracts (that from then on start in 
odd-numbered periods). The deviating even firm's real profit in period $T_{e}$ is the same as if did not deviate, i.e., $a_{T_{e}} k\left(A_{n_{o}, T_{e}}-c\right)$, and its discounted expected real profits at $T_{e}$ from all periods after $T_{e}$ is given by the expected value of concluding long contracts at odd-numbered periods starting in period $T_{e}+1$ and discounted one period, i.e., by the expected value at $T_{e}$ of expression (10) after $T_{e}+1$ has been substituted for $T_{o}$ and the expression multiplied by $1 /(1+\delta)$. Hence, a deviating even firm's total discounted expected real profits at $T_{e}$ is

$$
\begin{aligned}
& a_{T_{e}} k\left(A_{n_{o}, T_{e}}-c\right) \\
& +\frac{k}{1+\rho} \underset{T_{e}}{\mathrm{E}}\left\{a_{T_{e}+1}\left[A_{n_{e}, T_{e}+1}+\frac{\mathrm{E}_{t-1} A_{n_{e}, t}+(1+\delta) \mathrm{E}_{t-1}\left(A_{n_{o}, t} B_{t}\right)-(1+\delta)^{2} c}{\delta(2+\delta)}\right]\right\} .
\end{aligned}
$$

Since $\mathrm{E}_{T_{e}} a_{T_{e}+1} /(1+\rho)=a_{T_{e}} /(1+\delta)$ and $\mathrm{E}_{T_{e}} A_{n_{e}, T_{e}+1}=\mathrm{E}_{t-1} A_{n_{e}, t}$, this formula can be written as

$$
\begin{aligned}
& a_{T_{e}} k\left(A_{n_{o}, T_{e}}-c\right) \\
& +\frac{a_{T_{e}} k}{1+\delta}\left[\mathrm{E}_{t-1} A_{n_{e}, t}+\frac{\mathrm{E}_{t-1} A_{n_{e}, t}+(1+\delta) \mathrm{E}_{t-1}\left(A_{n_{o}, t} B_{t}\right)-(1+\delta)^{2} c}{\delta(2+\delta)}\right] \\
= & a_{T_{e}} k\left[A_{n_{o}, T_{e}}+\frac{(1+\delta) \mathrm{E}_{t-1} A_{n_{e}, t}+\mathrm{E}_{t-1}\left(A_{n_{o}, t} B_{t}\right)-\left(1+3 \delta+\delta^{2}\right) c}{\delta(2+\delta)}\right] .
\end{aligned}
$$

Subtracting the total discounted expected real profits for a non-deviating even firm (expression (8)), we obtain that an even firm's gain from deviating in period $T_{e}$ is

$$
\begin{aligned}
& a_{T_{e}} k\left[A_{n_{o}, T_{e}}+\frac{(1+\delta) \mathrm{E}_{t-1} A_{n_{e}, t}+\mathrm{E}_{t-1}\left(A_{n_{o}, t} B_{t}\right)-\left(1+3 \delta+\delta^{2}\right) c}{\delta(2+\delta)}\right] \\
& -a_{T_{e}} k\left[A_{n_{o}, T_{e}}+\frac{\mathrm{E}_{t-1} A_{n_{o}, t}+(1+\delta) \mathrm{E}_{t-1}\left(A_{n_{e}, t} B_{t}\right)-(1+\delta)^{2} c}{\delta(2+\delta)}\right] \\
= & a_{T_{e}} h\left\{\mathrm{E}_{t-1}\left[A_{n_{e}, t}\left(1-B_{t}\right)\right]-\frac{\mathrm{E}_{t-1}\left[A_{n_{o}, t}\left(1-B_{t}\right)\right]+\delta c}{1+\delta}\right\} \\
= & a_{T_{e}} h\left[-D\left(n_{e}\right)+\frac{D\left(n_{o}\right)}{1+\delta}\right] \\
= & a_{T_{e}} h G\left(n_{e}, n_{o}\right) .
\end{aligned}
$$

The gain of discounted expected real profits for a short-contract firm that deviates in period $T_{o}$ by concluding a long contract and in period $T_{o}+2$ reverts to always concluding short contracts can be obtained from expression (A9) by substituting $T_{o}$ for $T_{e}$ and $n_{o}$ for $n_{e}$. 
This yields $a_{T_{o}} k D\left(n_{o}\right) /(1+\delta)$. Similarly, the gain of discounted expected real profits for an odd firm that deviates in period $T_{o}$ by concluding a short contract and in period $T_{o}+1$ reverts to always concluding long contracts (that from then on start in even-numbered periods) can be obtained from expression (A10) by substituting $T_{o}$ for $T_{e}$ and interchanging $n_{o}$ and $n_{e}$. This yields $a_{T_{o}} h G\left(n_{o}, n_{e}\right)$.

\section{Proof of Lemma 3}

Differentiating $D(n)$ with respect to $n$ yields

$$
\frac{d D(n)}{d n}=-x \mathrm{E}_{t-1}\left[\frac{\left(B_{t}-1\right)^{2}}{\left(1-n+n B_{t}\right)^{1+x}}\right]
$$

which is negative.

\section{Appendix B}

\section{Proof of Proposition 1}

Regime 1: If $c \leq c_{1}$, then $D(0) \leq 0$ and the candidate strategy for each firm is to always conclude short contracts. We need to show that if $n_{1}=1$, then a short-contract firm cannot gain from a one-time deviation from the candidate strategy by concluding a long contract and afterwards always concluding short contracts. According to Lemma 2, if $n_{1}=1$, then the gain of a short-contract firm that deviates from the candidate strategy is proportional to $D(0)$, and hence nonpositive. The candidate strategy is therefore optimal.

Regime 2: If $c_{1}<c<c_{2}$, then $D\left(\frac{1}{2}\right)<0<D(0)$ and the candidate strategy for each firm is to always conclude a similar contract whenever the old contract expires. This makes each firm either a short-contract firm, an even firm, or an odd firm. We need to show that if $n_{1}=1-2 m$ and $n_{e}=n_{o}=m$, then a short-contract firm cannot gain from a onetime deviation from the candidate strategy by concluding a long contract and afterwards always concluding short contracts, and, likewise, that a long-contract firm cannot gain from deviating from the candidate strategy by concluding a short contract and afterwards always concluding long contracts. According to Lemma 2, if $n_{1}=1-2 m$ and $n_{e}=n_{o}=m$, then 
the gain for a short-contract firm that deviates from the candidate strategy is proportional to $D(m)$, while the gain for a long-contract firm that deviates from the candidate strategy is proportional to $-D(m)$. Since $D(m)=0$, these gains are zero, and the candidate strategy is therefore optimal.

Regime 3: If $c_{2} \leq c<c_{3}$, then $G\left(\frac{1}{2}, \frac{1}{2}\right) \leq 0<G(1,0)$ and the candidate strategy is to conclude a long contract whenever the old contract expires, which makes each firm either an even or an odd firm. We need to show that a long-contract firm cannot gain from a onetime deviation from the candidate strategy by concluding a short contract and afterwards always concluding long contracts. According to Lemma 2, if $n_{1}=0, n_{e} \in[1-\hat{m}, \hat{m}]$, and $n_{o}=1-n_{e}$, then the gain for an even firm that deviates from the candidate strategy in period $T_{e}$ is $a_{T_{e}} h G\left(n_{e}, 1-n_{e}\right)$, and the gain for an odd firm that deviates from the candidate strategy in period $T_{o}$ is $a_{T_{o}} h G\left(n_{o}, 1-n_{o}\right)$. If $n_{e} \leq \hat{m}$, then $G\left(n_{e}, 1-n_{e}\right) \leq 0$ so that an even firm does not gain from deviating, and if $n_{o} \leq \hat{m}$, then $G\left(n_{o}, 1-n_{o}\right) \leq 0$ so that an odd firm does not gain from deviating. Consequently, if $n_{e} \in[1-\hat{m}, \hat{m}]$, then $G\left(n_{e}, 1-n_{e}\right) \leq 0$ and $G\left(n_{o}, 1-n_{o}\right) \leq 0$ so that no firm can gain from deviating. The candidate strategy is therefore optimal.

Regime 4: If $c_{3} \leq c$, then $G(1,0) \leq 0$ and the candidate strategy is to conclude a long contract whenever the old contract expires, which makes each firm either an even or an odd firm. As in Regime 3, we need to show that a long-contract firm cannot gain from a one-time deviation from the candidate strategy by concluding a short contract and afterwards always concluding long contracts. According to Lemma 2, if $n_{1}=0, n_{e} \in[0,1]$ and $n_{o}=1-n_{e}$, then the gain for an even firm that deviates from the candidate strategy in period $T_{e}$ is $a_{T_{e}} h G\left(n_{e}, 1-n_{e}\right)$, and the gain for an odd firm that deviates from the candidate strategy in period $T_{o}$ is $a_{T_{o}} h G\left(n_{o}, 1-n_{o}\right)$. Since $G\left(n_{e}, 1-n_{e}\right) \leq 0$ for any $n_{e}$ and $G\left(n_{o}, 1-n_{o}\right) \leq 0$ for any $n_{o}$, no firm can gain from deviating, and the candidate strategy is therefore optimal.

This completes the proof of Proposition 1. 


\section{Appendix C}

\section{Proof of Proposition 2}

To determine the effect of $c$ on $m$, differentiate $D(m)=0$ with respect to $c$. This yields

$$
\frac{d m}{d c}=-\frac{1}{\partial D(n) / \partial n}
$$

where $\partial D(n) / \partial n$ is evaluated at $n=m$. Since $\partial D(n) / \partial n<0$, it follows that $d m / d c>0$.

To determine the effect of $c$ on $\hat{m}$, differentiate $G(\hat{m}, 1-\hat{m})=0$ with respect to $c$. This yields

$$
\frac{d \hat{m}}{d c}=\frac{\delta}{(1+\delta) d G(n, 1-n) / d n}
$$

where $d G(n, 1-n) / d n$ is evaluated at $n=\hat{m}$. Since $d G(n, 1-n) / d n>0$, it follows that $d \hat{m} / d c>0$.

To determine the effect of $c$ on $s$, we use the definition of $s$ to obtain that

$$
\frac{d s}{d c}=-\frac{d \hat{m} / d c}{\hat{m}^{2}}<0 .
$$

\section{Proof of Proposition 3}

Clearly, $d m / d \rho=0$. To determine the effect of $\rho$ on $\hat{m}$, differentiate $G(\hat{m}, 1-\hat{m})=0$ with respect to $\rho$. This yields

$$
\frac{d \hat{m}}{d \rho}=\frac{(1+\xi) D(1-\hat{m})}{(1+\rho)^{2} d G(n, 1-n) / d n},
$$

where $d G(n, 1-n) / d n$ is evaluated at $n=\hat{m}$. Since $D(1-\hat{m})>0$ and $d G(n, 1-n) / d n>0$, it follows that $d \hat{m} / d \rho>0$. Furthermore,

$$
\frac{d s}{d \rho}=-\frac{d \hat{m} / d \rho}{\hat{m}^{2}}<0
$$




\section{Proof of Proposition 4}

Clearly, $d m / d \xi=0$. To determine the effect of $\xi$ on $\hat{m}$, differentiate $G(\hat{m}, 1-\hat{m})=0$ with respect to $\xi$. This yields

$$
\frac{d \hat{m}}{d \xi}=-\frac{D(1-\hat{m})}{(1+\rho) \partial G(n, 1-n) / \partial n}
$$

where $\partial G(n, 1-n) / \partial n$ is evaluated at $n=\hat{m}$. Since $D(1-\hat{m})>0$ and $\partial G(n, 1-n) / \partial n>0$, it follows that $d \hat{m} / d \xi<0$. Furthermore,

$$
\frac{d s}{d \xi}=-\frac{d \hat{m} / d \xi}{\hat{m}^{2}}>0
$$

\section{Proof of Proposition 5}

It is clear that $d c_{1} / d \rho=d c_{2} / d \rho=0$. Differentiating $c_{3}$ with respect to $\rho$ yields

$$
\begin{aligned}
\frac{d c_{3}}{d \rho} & =-\frac{1+\xi}{(\rho-\xi)^{2}} \underset{t-1}{\mathrm{E}}\left[\left(A_{1 t}-A_{0 t}\right)\left(1-B_{t}\right)\right] \\
& =-\frac{1+\xi}{(\rho-\xi)^{2}} \underset{t-1}{\mathrm{E}}\left[\left(\frac{1}{B_{t}^{x}}-1\right)\left(1-B_{t}\right)\right]
\end{aligned}
$$

which is negative since the term in the square bracket is positive for all $B_{t} \neq 1$. Hence, $d c_{3} / d \rho<0$.

\section{Proof of Proposition 6}

It is clear that $d c_{1} / d \xi=d c_{2} / d \xi=0$. Differentiating $c_{3}$ with respect to $\xi$ yields

$$
\begin{aligned}
\frac{d c_{3}}{d \xi} & =\frac{1+\rho}{(\rho-\xi)^{2}} \underset{t-1}{\mathrm{E}}\left[\left(A_{1 t}-A_{0 t}\right)\left(1-B_{t}\right)\right] \\
& =\frac{1+\xi}{(\rho-\xi)^{2}} \underset{t-1}{\mathrm{E}}\left[\left(\frac{1}{B_{t}^{x}}-1\right)\left(1-B_{t}\right)\right],
\end{aligned}
$$

which is positive since the term in the square brackets is positive for all $B_{t} \neq 1$. Hence, $d c_{3} / d \xi>0$. 


\section{References}

Andersen, T.M., 1998. Persistency in sticky price models. European Economic Review 42, 593-603.

Ascari, G., 2000. Optimising agents, staggered wages and persistence in the real effects of money shocks. Economic Journal 110, 664-686.

Ball, L., 1987. Externalities from contract length. American Economic Review 77, 615-629.

Christiano, L.J., Eichenbaum, M., Evans, C.L., 2005. Nominal rigidities and the dynamic effects of a shock to monetary policy. Journal of Political Economy 113, 1-45.

Christofides, L.N., 1990. The interaction between indexation, contract duration and noncontingent wage adjustment. Economica 57, 395-409.

Christofides, L.N., Peng, C., 2006. Contract duration and indexation in a period of real and nominal uncertainty. Labour Economics 13, 61-86.

Clarida, R., Gali, J., Gertler, M., 1999. The science of monetary policy: A new Keynesian perspective. Journal of Economic Literature 37, 1661-1707.

Danziger, L., 1988. Real shocks, efficient risk sharing, and the duration of labor contracts. Quarterly Journal of Economics 103, 435-440.

Dye, R.A., 1985. Optimal length of labor contracts. International Economic Review 26, 251-270.

Ehrenberg, R. G., Danziger, L., San, G., 1984. Cost-of-living adjustment clauses in union contracts. Research in Labor Economics 6, 1-63.

Erceg, C.J., Henderson, D.W., Levin, A.T., 2000. Optimal monetary policy with staggered wage and price contracts. Journal of Monetary Economics 46, 281-313.

Fethke, G., Policano, A., 1986. Will wage setters ever stagger decisions? Quartely Journal of Economics 101, 867-877.

Fethke, G., Policano, A., 1987. Monetary policy and the timing of wage negotiations. Journal of Monetary Economics 19, 89-105.

Fethke, G., Policano, A., 1990. Information incentives and contract timing patterns. International Economic Review 31, 651-665. 
Gray, J.A., 1978. On indexation and contract length. Journal of Political Economy 86, 1-18. Harris, M., Holmstrom, B., 1987. On the duration of agreements. International Economic Review 28, 389-406.

Huang, K.X.D., Liu, Z., 2002. Staggered price-setting, staggered wage-setting, and business cycle persistence. Journal of Monetary Economics 49, 405-433.

Matsukawa, S., 1986. The Equilibrium Distribution of Wage Settlements and Economic Stability. International Economic Review 27, 415-437.

Murphy, K.J., 1992. Determinants of contract duration in collective bargaining agreements. Industrial and Labor Relations Review 45, 352-365.

Olivei, G., Tenreyro, S., 2007. The timing of monetary policy shocks. American Economic Review 97, 636-663.

Olivei, G., Tenreyro, S., 2008. Wage setting patterns and monetary policy: International evidence. CEP Discussion Paper No 872.

Rich, R., Tracy, J., 2004. Uncertainty and labor contract durations. Review of Economics and Statistics 86, 270-287.

Smets, F., Wouters, R., 2007. Shocks and frictions in US business cycles: A Bayesian DSGE approach. American Economic Review 97, 586-606.

Taylor, J.B., 1980. Aggregate dynamics and staggered contracts. Journal of Political Economy $88,1-23$.

Wallace, F.H., 2001. The effects of shock size and type on labor-contract duration. Journal of Labor Economics 19, 658-681. 


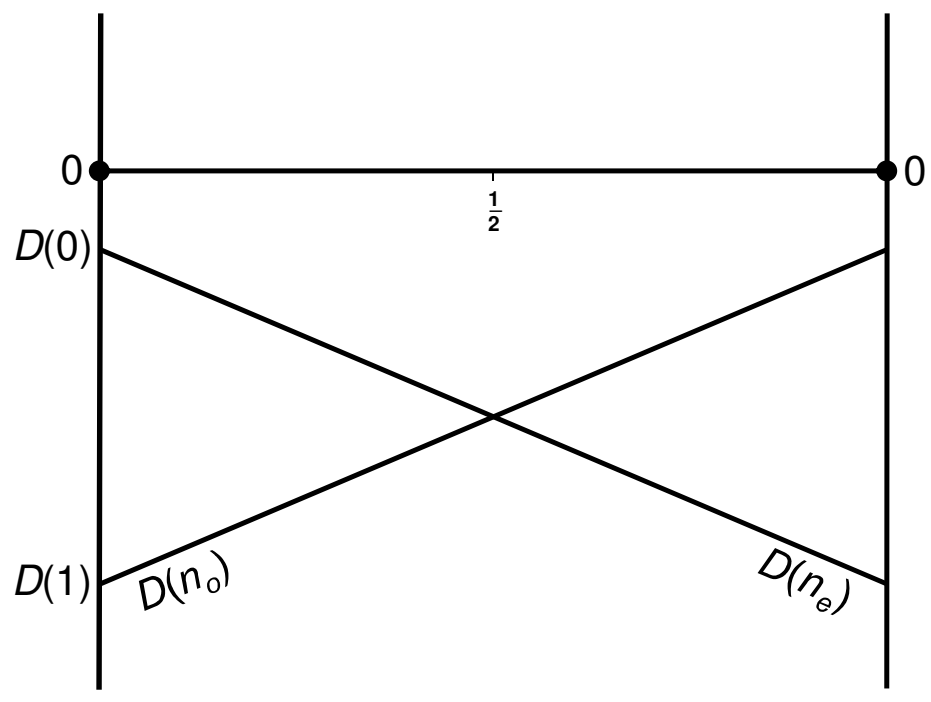

(a): Regime 1

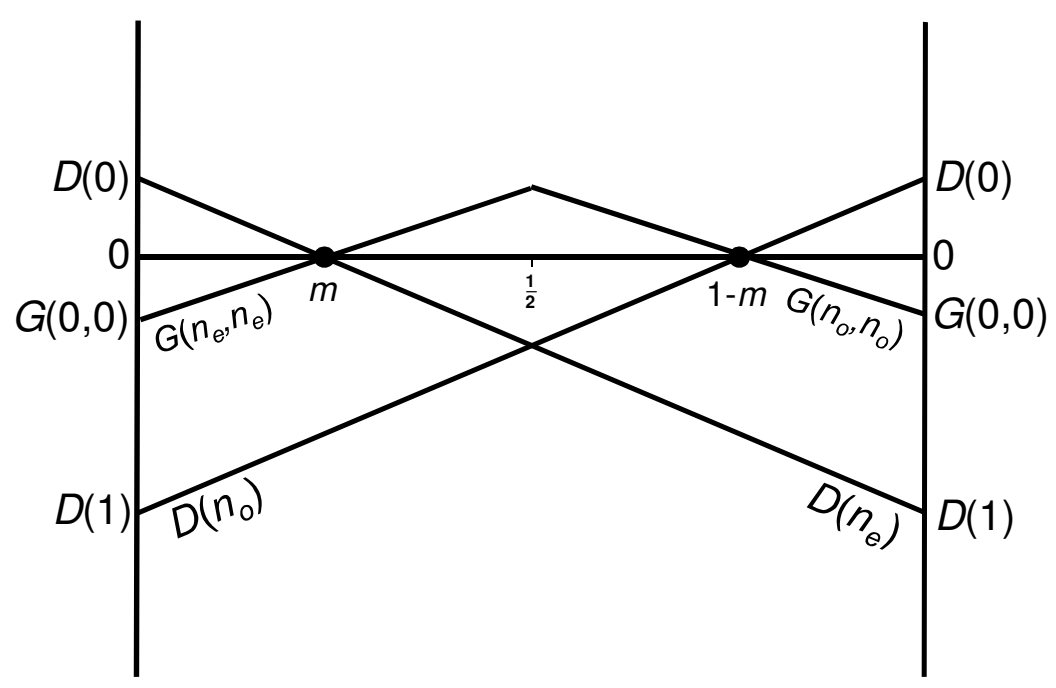

(b): Regime 2 


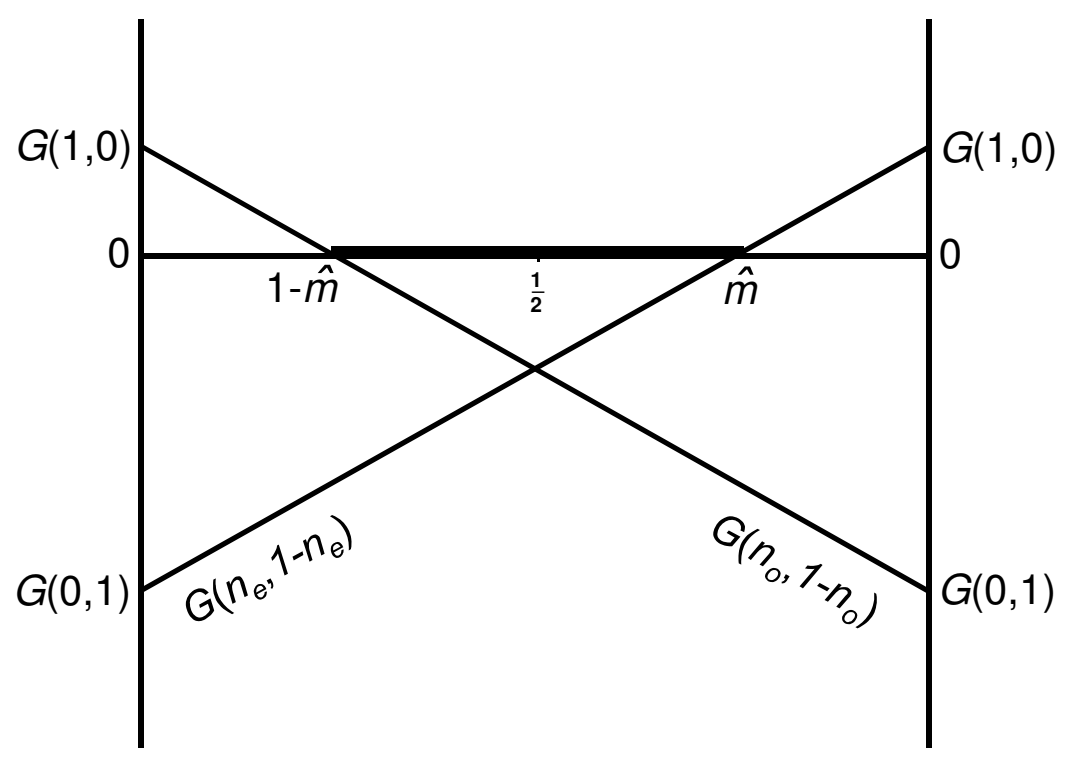

(c): Regime 3

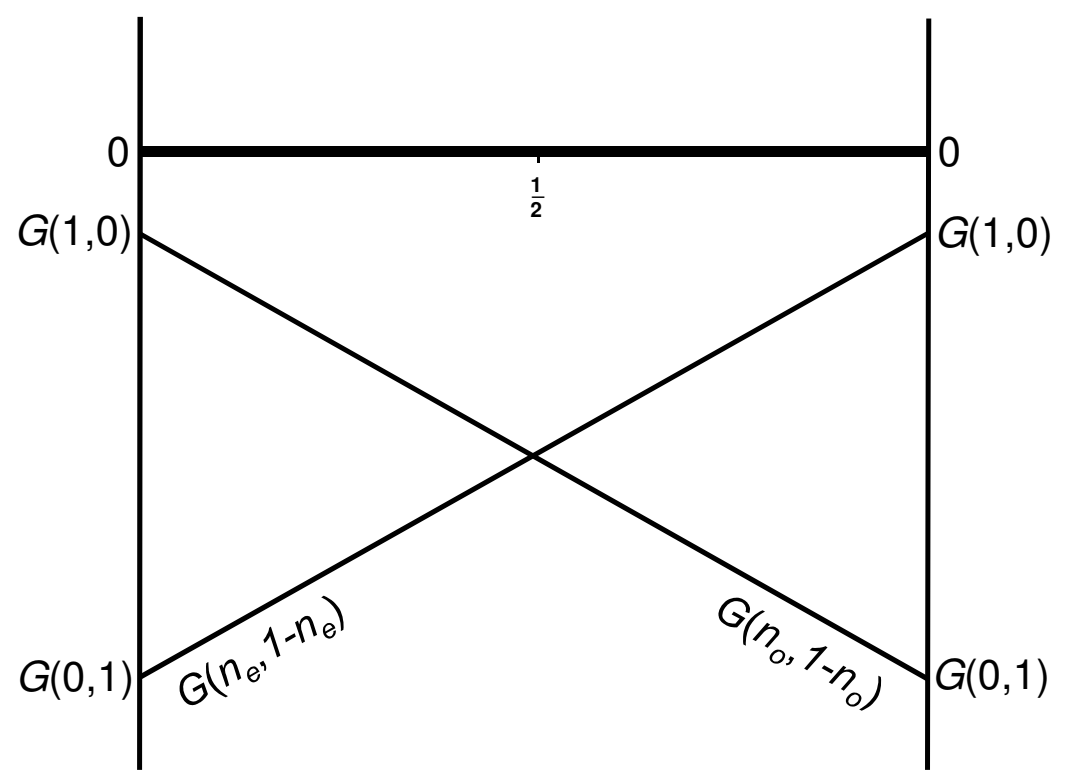

(d): Regime 4

FIGURE 1: THE EQUILIBRIA 